【論文】

\title{
多孔 Si 薄膜の熱・電気輸送特性 Thermal and Electrical Transport Properties of Porous Si Thin Films
}

\author{
萩野春俊*,** 岩田尚* 谷村直樹**,*** 宮崎康次 ${ }^{*}, * *$ \\ Harutoshi Hagino, Hisashi Iwata, Naoki Tanimura and Koji Miyazaki
}

\begin{abstract}
微細構造による熱・電気輸送特性への影響を調べるため MEMS 技術を用いて微細孔構造を持つ薄膜 Si マイクロブリッジを作製し, 通電加熱により面方向の熱・電気伝導率を測定した. 微細孔構造の存 在により, 熱・電気伝導率は減少した。特に熱伝導率は孔の配置や孔間隔に応じて異なる減少を示し た. 熱輸送を担うフォノンの平均自由行程は電気輸送を担う電子の平均自由行程より長いため, 微細 構造中においてフォノンの輸送は準弹道輸送となり，一方で電子輸送は拡散輸送だったため，熱・電 気輸送は微細構造に対して異なる応答を示したと考えられる.
\end{abstract}

We studied the effects of micro-structures on both thermal and electrical transport by making $\mathrm{Si}$ thin films with micro-pores. The in-plane thermal and electrical conductivity of the Si thin films were measured simultaneously by using a self-heating method. Both of thermal and electrical conductivity of porous Si thin films were lower than those of Si thin film without pores. The huge reductions of thermal conductivities were measured although the reductions of electrical conductivity were explained by classical model. The mean free path of phonon is much longer than the characteristic length of porous Si thin films. The semi-ballistic phonon transport caused huge reduction of thermal conductivity of micro-structured Si thin films.

[Keywords: Silicon, Thermal conductivity, Electrical conductivity, Phonon mean free path]

\section{1.はじめに}

近年微細加工技術の発達に伴い，ナノドット[1], ナノ ワイヤー[2,3], 超格子構造[4,5], 微細孔構造[6-8]等マイク ロ,ナノオーダーの構造を用いて物性を制御する研究が 盛んに行われており，自然界に存在しない熱・電気物性 を持つ物質を作製した研究が数多く報告されている.こ れらはフォノンによる熱輸送と電子による電気輸送を微 細構造によって制御することで達成されている。 一般

* 九州工業大学 大学院工学研究院 機械知能工学研究系,

厂804-8550 福岡県北九州市戸畑区仙水町 1-1.

Department of Mechanical and Control Engineering, Kyushu Institute of Technology, 1-1 Sensui-cho, Tobata-ku, Kitakyushu, Fukuoka 804-8550.

FAX: 093-884-3168 E-mail: miyazaki@mech.kyutech.ac.jp

** 技術研究組合 BEANS 研究所 Life BEANS センター九州 T819-0395 福岡県福岡市西区元岡 744.

Life BEANS Center Kyushu, 744 Motooka, Nishi-ku, Fukuoka, Fukuoka 819-0395.

***みずほ情報総研株式会社 サイエンスソリューション部 バ イオエンジニアリングチーム

厂101-8443 東京都千代田区神田錦町 2-3.

Mizuho Information \& Research Institute, 2-3 Nishiki-cho, Kanda, Chiyoda-ku, Tokyo 101-8443.

Fax: 03-5281-5331 E-mail: naoki.tanimura@mizuho-ir.co.jp
にフォノンと電子の平均自由行程の長さが異なるため, 同じ微細構造中において構造や界面により受ける影響が 異なり，結果としてフォノンと電子が異なる輸送特性を 示すことがある.これを利用した例として, 熱から電気 一直接変換を行う熱電半導体が挙げられる. 熱電半導体 中にフォノンの平均自由行程より小さく, 電子の平均自 由行程より大きい代表寸法を持つナノ構造を設けると, 構造界面においてフォノンの散乱のみが増加するためフ オノンによる熱輸送が低減する。一方で電子輸送は古典 的な範囲で構造の影響を受けるのみで, 大きな電気的特 性の低下は見られず，結果として高い熱電特性が得られ ることが報告されている[3-5,7,9,10]. 微細構造を用いた物 性制御ではフォノンと電子の平均自由行程に焦点を絞り, 微細構造の寸法効果を用いて構造設計を行う場合が多い が，実際にフォノンと電子が構造からどのような影響を 受けつつ輸送されているか把握する必要がある.

本研究では微細構造による熱・電子輸送特性への影響 を調べるため, MEMS 技術を用いた選択的エッチングに より微細孔構造を有する自立膜からなる薄膜 $\mathrm{Si}$ マイクロ ブリッジを作製した．面方向熱・電気伝導率の測定は自 立膜部を通電加熱により自己発熱させ，発熱時の電気抵 抗から同時測定した，測定結果から物性を得るには，通 
電加熱時のジュール発熱と, 発熱に伴う熱伝導を把握す る必要があり, COMSOL Multiphysics を用いて数值解析し た. 数值解析結果をもとに解析モデルを簡単化し, 測定 結果から熱, 電気伝導率を得て, 微細構造が熱・電気輸 送に与える影響を考察した。

\section{2. 測定原理}

薄膜 $\mathrm{Si}$ マイクロブリッジの全体図を図 1 に示す。マイ クロブリッジは 4 つの電極部（図 1(a)）と微細孔構造を持 つ自立膜(図1(b)) からなるブリッジ構造となっている[11]. 自立膜部がジュール発熱し, 両端は温度 $T_{0}$ で一定である と仮定すると図 2 のような温度分布が得られる. 定常状 態における一次元熱伝導方程式の解より温度分布 $T$ は以 下の式となる.

$$
T=-\frac{q}{2 \kappa} x^{2}+\frac{q L}{2 \kappa} x+T_{0}
$$

ここで $q$ は単位体積あたりの発熱量 $\left[\mathrm{W} / \mathrm{m}^{3}\right]$, ↔は見かけの 熱伝導率 $[\mathrm{W} /(\mathrm{m} ・ \mathrm{~K})], L$ はブリッジの長さ $[\mathrm{m}], T_{0}$ はブリ ッジ端部の温度 $[\mathrm{K}]$ である. ブリッジの平均発熱温度 $T_{A V E}$ は，式(1)を積分してブリッジ部の長さで平均すると求め られる。

$$
T_{A V E}=\frac{1}{L} \int_{0}^{L} T d x=T_{0}+\frac{q L^{2}}{12 \kappa}
$$

これよりッは次式で得られる.

$$
\kappa=\frac{q L^{2}}{12\left(T_{A V E}-T_{0}\right)}
$$

このとき見かけの電気伝導率 $\sigma\left[\Omega^{-1} \cdot \mathrm{m}^{-1}\right]$ は発熱時の電 気抵抗 $R[\Omega]$ とマイクロブリッジの各寸法要素(ブリッ ジの断面積 $A\left[\mathrm{~m}^{2}\right]$, ブリッジ長さ $L[\mathrm{~m}]$ )を用いて次式で 求まる.

$$
\sigma=\frac{L}{R A}
$$

次式のように電気伝導率の温度依存性を $T_{A V E}$ に対して予

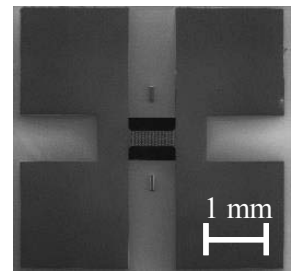

(a) Top view

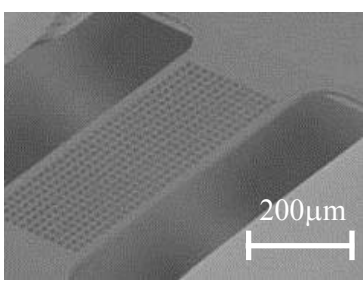

(b) Birds-eye view
Fig. 1 SEM images of a free standing Si micro-bridge

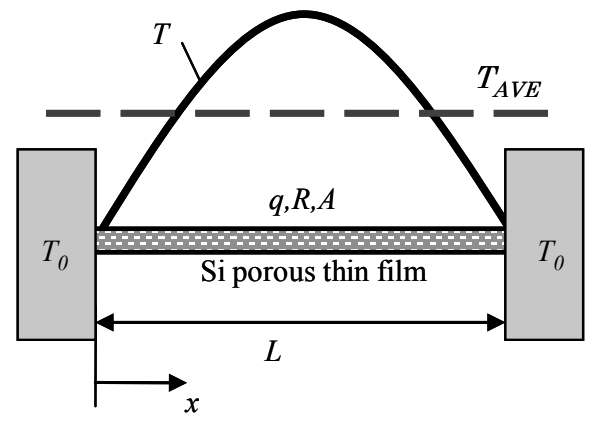

Fig. 2 Analytical model of a self-heating method

め較正しておくことでブリッジの平均温度が得られ，見 かけの熱伝導率が得られる[12].

$$
R_{\text {meas }}=R_{\text {ref }}+\alpha\left(T_{A V E}-T_{0}\right)
$$

ここで $は$ はブリッジ部電気抵抗の温度係数である.

\section{3. 数值解析}

通電加熱時の発熱による解析モデルの妥当性を確認す るため, 発熱時の温度分布を電気伝導と熱伝導を同時に 扱う汎用シミュレーションソフト (COMSOL Multiphysics）を用いて温度分布を計算した。見かけの物 性值での応答を得るため, フォノン（熱）もエレクトロ ン（電気）も拡散輸送を仮定した。 Maxwell 方程式を用 いて自立膜に生じている電界から構造中の電流密度を計 算しジュール発熱分布を求め, この発熱分布を用いて定 常状態における温度分布を熱伝導方程式の数值解析から 得た. 解析モデルは長さ $280 \mu \mathrm{m}$, 膜厚 $2 \mu \mathrm{m}$, 幅 $90 \mu \mathrm{m}$ の 自立膜構造で, 孔間隔が $5,6,7.5,10,15 \mu \mathrm{m}$ として孔を周 期的に配列した.この時の孔の幅は孔間隔の 2 倍であり， ブリッジ幅を調整して空隙率が同じになるよう設定した. 


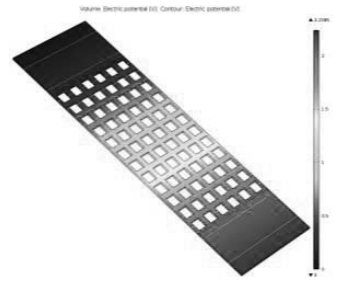

(a) Overall of electrical potential distribution

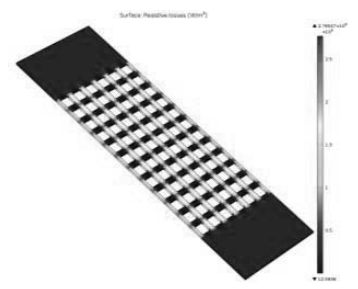

(c) Overall of joule heating distribution

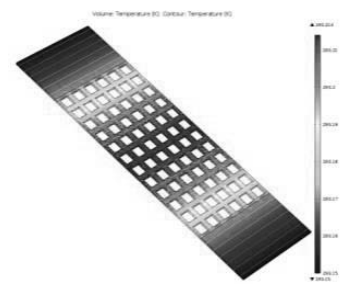

(e) Overall of temperature distribution

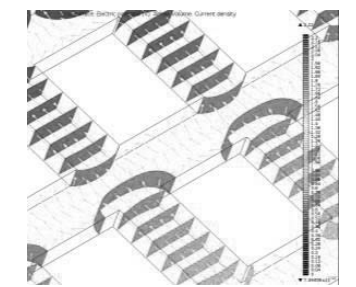

(b) Electrical potential distribution in porous

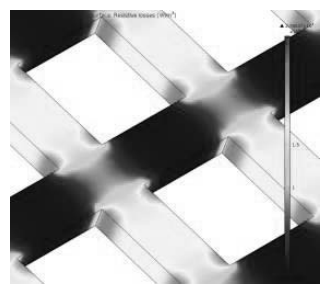

(d) Joule heat generation distribution in porous

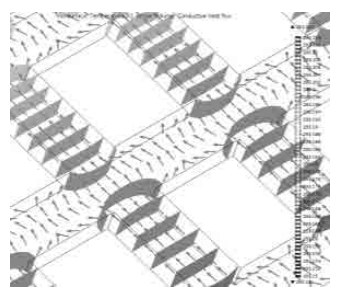

(f) Heat flux distribution in porous
Fig. 3 Calculated results of a self-heating porous thin film

多孔構造は端部より $50 \mu \mathrm{m}$ 離れた地点より存在する. 初期 条件は $20^{\circ} \mathrm{C}$ 䨌囲気下で, 真空中において $20 \mu \mathrm{A}$ で発熱さ せた時の温度, 電位, ジュール発熱分布を解析した。境 界条件としてブリッジ端部を $20^{\circ} \mathrm{C}$ 等温とした。一例と して孔間隔 $5 \mu \mathrm{m}$ 時の各分布についての解析結果を図 3 に 示す. ジュール発熱は電流の分布を追従しており, 長さ 方向の通路部分で良く発熱して一様に発熱していなかっ たが（図 3 (c)），熱伝導の数值解析結果としては, 熱伝 導が熱の拡散輸送現象であるため, 局所的な分布が鈍さ れて, 長さ方向に一次元的な温度分布となった(図3 (e)). 孔間隔を $5,6,7.5,10,15 \mu \mathrm{m}$ に設定した際の電圧分布を図 4 に，定常状態における温度分布を図 5 に示寸，各分布は 発熱時の構造中央部における状態を比較している. 温度 分布は細孔・通路の構造により局所的に凹凸が生じたが

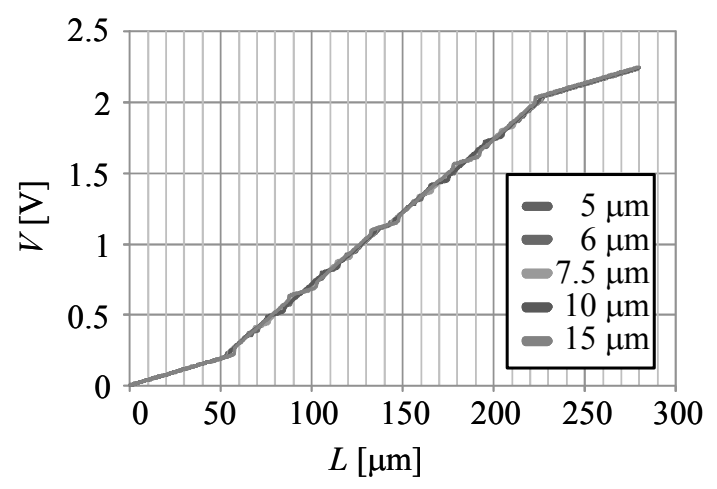

Fig. 4 Distance between holes dependence of spatially averaged electrical potential calculated by COMSOL Multiphysics

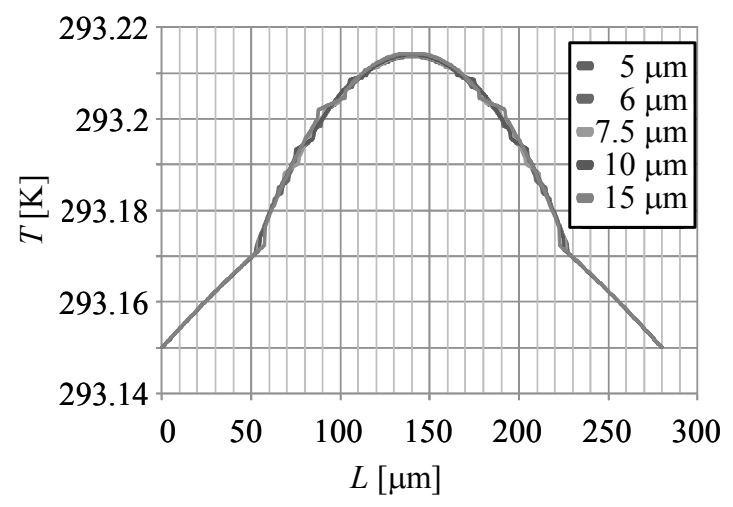

Fig. 5 Distance between holes dependence of spatially averaged temperature distribution calculated by COMSOL Multiphysics

各孔構造において温度分布の概形には大きな違いはなか った. ブリッジ端部の孔を持たない部分における温度分 布の変化は孔構造部の二次曲線的な温度の変化よりも変 化量が少ない. この数值解析結果を参考として, 構造を 持つブリッジの熱伝導率を式(3)で求める時には, 構造を 持たない部分での発熱による温度上昇から構造部端部の 温度を求め, 通電加熱により得られた平均発熱温度から 差し引くことで構造部のみの平均発熱温度を計算する.

\section{4. 実験方法}

\section{$4.1 \mathrm{Si}$ マイクロブリッジの作製}

SOI（Silicon-on-Insulator）基板を加工することで $\mathrm{Si}$ マイ クロブリッジを作製した. SOI は Si 基板上に絶縁層の薄 膜 $\mathrm{SiO}_{2}$ と薄膜の $\mathrm{Si}$ が積層されて構成されている(図6 (a)). 


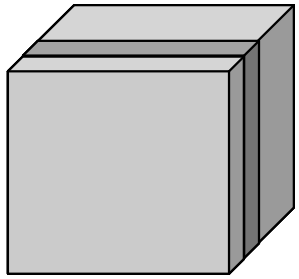

(a) SOI wafer

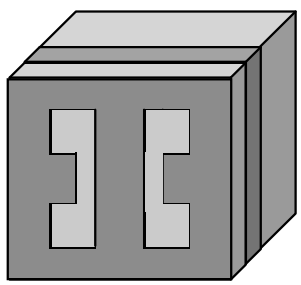

(b) $\mathrm{SiO}_{2}$ patterning and ion doping

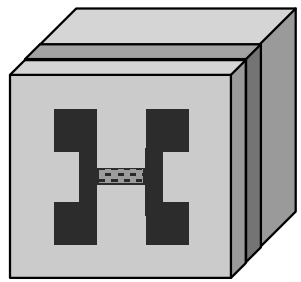

(c) Patterning

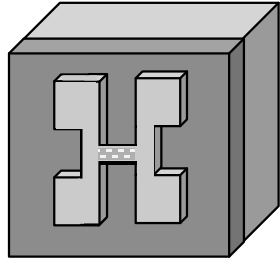

(d) Si etching in $\mathrm{KOH}$
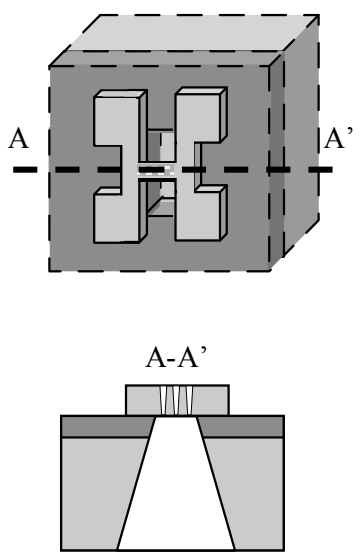

(e) Back etching of $\mathrm{Si}$ and $\mathrm{SiO}_{2}$

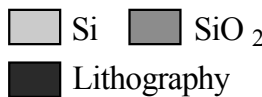

Fig. 6 Fabrication steps of a free-standing Si membrane in SOI wafer

電極部を作製するためにイオン注入機でリンを注入し た。この時フォトリソグラフィによるパターンニングを 行い電極部以外に $\mathrm{SiO}_{2}$ を成膜し, 電極部にのみ選択的に イオンが注入されるようにした（図 6 (b)）． $\mathrm{SiO}_{2}$ を除去 後 $\mathrm{Si}$ 上にフォトリソグラフィを用いて目的のブリッジ構 造を持つマスクを作製した（図 6 (c)）。次にRIEによる 選択的エッチングを行い, マイクロブリッジのパターン を作製した。このとき同時に微細孔構造部のエッチング も行った(図 6(d)). 次に自立膜ブリッジ裏側の $\mathrm{Si}$ を $\mathrm{KOH}$ によるウェットエッチングで除去するが，表面の $\mathrm{Si}$ を保 護するための保護膜をプラズマCVDによりパターン上に 成膜する. エッチング時に薄膜 $\mathrm{Si}$ と絶縁層の $\mathrm{SiO}_{2}$ の内部 応力により自立膜部が破損するため $\mathrm{SiN}$ と $\mathrm{SiO}_{2}$ からなる 保護膜をブリッジのパターン表面に成膜し, 応力を緩和 させた. エッチング後, 保護膜( $\mathrm{SiN}$ 層と $\mathrm{SiO}_{2}$ 層)とブリッ 漅面の絶縁層 $\left(\mathrm{SiO}_{2}\right.$ 層)を $\mathrm{BHF}$ 溶液中で選択的に除去す

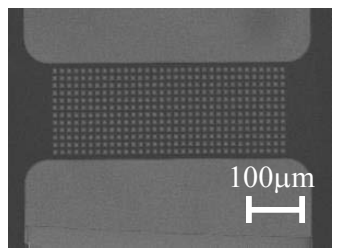

(a) Porous bridge

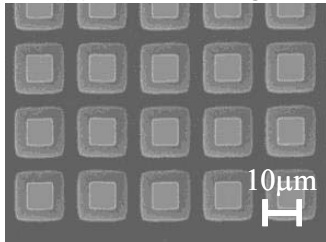

(c) Pattern 2

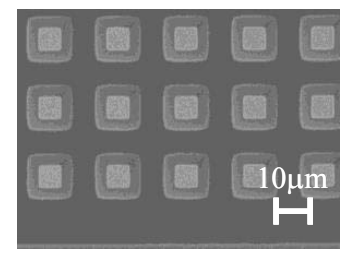

(b) Pattern 1

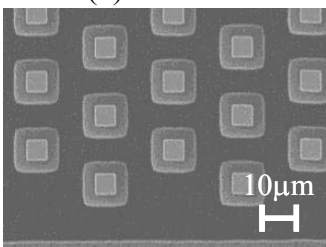

(d) Pattern 3
Fig. 7 SEM images of free-standing porous Si micro bridges

ることで薄膜 Si 自立膜ブリッジとし，熱と電気の流れを 同一方向になるようにした（図 6 (e)）。電極部にはアル ミを蒸着した，ブリッジ寸法は幅 $200 \mu \mathrm{m}$ ，厚さ $2 \mu \mathrm{m}$ ，長 さ $600 \mu \mathrm{m}$ である. 各微細周期孔構造の SEM 像を図 7 に示 す. 微細孔構造が熱輸送, 電気輸送に与える影響を調べ るため, 微細孔構造を持たないものと 3 種類の微細孔構 造を用意した。 孔構造は作製時の制限により端部から $50 \mu \mathrm{m}$ 離れた地点から存在する. パターン 1 は $10 \mu \mathrm{m}$ の孔 が孔間隔 $5 \mu \mathrm{m}$ で格子状に配列されている，パターン 2 は $11 \mu \mathrm{m}$ の孔が孔間隔 $3 \mu \mathrm{m}$ で格子状に配列され, パターン 3 ではパターン 1 と同じ孔を孔間隔 $5 \mu \mathrm{m}$ で千鳥状に配列し ている. 3 種類の構造はいずれも空隙率が同じになるよう に孔を配置しブリッジ幅を調整した。

\section{2 熱・電気伝導率の同時測定}

熱・電気伝導率測定は真空チャンバー内に設置したマ イクロブリッジに直流電圧 $(1 \mathrm{~V}, 100 \mathrm{~mA})$ を印加し, ジュー ル発熱させながら，ブリッジ部の電気抵抗を測定するこ とで進めた. 熱伝導率はブリッジ平均発熱温度 $T_{A V E}$, 発 熱時の端部温度 $T_{0}$, 発熱量から求める. ブリッジ平均発 熱温度 $T_{A V E}$ は発熱時の電気抵抗から求めた。 電気抵抗の 温度依存性は真空チャンバー内で液体窒素とヒーターに より温度制御したマイクロブリッジの電気抵抗を 4 端子 法により測定して求めた.この時マイクロブリッジの自 立膜部は真性半導体となるよう不純物をドープせず，電 気抵抗は温度に対して単調増加した。構造を持たないマ イクロブリッジの端部温度 $T_{0}$ は熱電対を用いて測定し, 


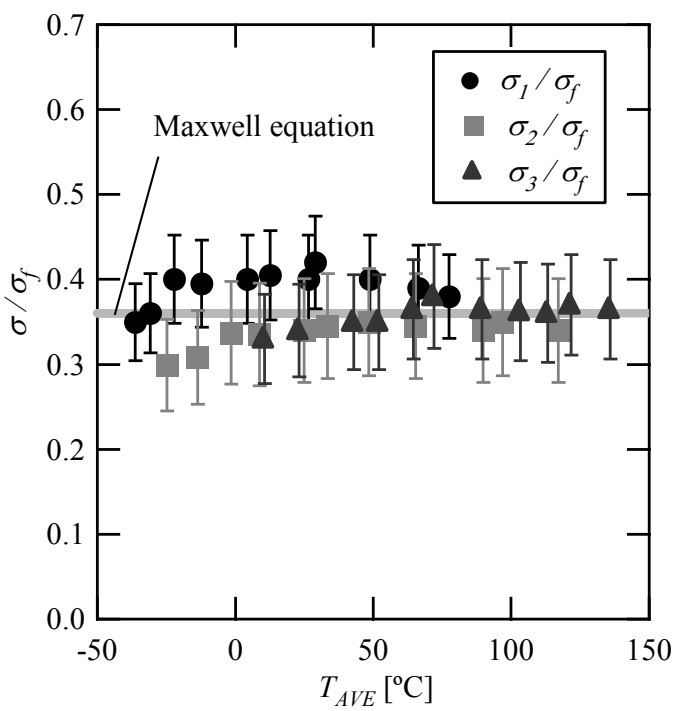

Fig.8 Measured electrical conductivity of porous Si thin films

構造を有するマイクロブリッジの場合には図 5 に示す温 度分布を仮定し, 構造を持たないブリッジ部の熱伝導率 と電気伝導率を用いて, 構造部と非構造部の境界温度を 端部温度 $T_{0}$ から求め, それを改めて $T_{0}$ とした。 ブリッ ジ長さ $L$ もその分短くする. 発熱量は印加した電流と電 圧から得た。

\section{5. 実験結果と考察}

-100 $0{ }^{\circ} \mathrm{C}$ において対象の $\mathrm{Si}$ 薄膜の熱伝導率，電気伝導 率を測定した. 各温度の平均発熱温度をパラメータとし, 構造の有無による電気伝導率の比を図 8 , 熱伝導率の比を 図 9 に示す.ここで添字の $f$ は構造無し, 各番号は各パタ ーンと対応している. 各パターンにおいて薄膜化による 熱, 電気伝導率への影響と構造による影響が混在してい るが, 構造の有無による熱, 電気伝導率の比を見ることで 構造による影響を評価することができる.ここで通電加 熱による測定では平均発熱温度を用いて物性を測定する が，図 2 のように温度分布をとる。電気伝導率，熱伝導 率は温度依存性を持つため最高温度, 最低温度において 物性が異なる. 最高温度, 最低温度における各物性を求 めエラーバーとして示した. 電気伝導率については構造 の空隙率をほぼ等しくなるように作製しているため, 電

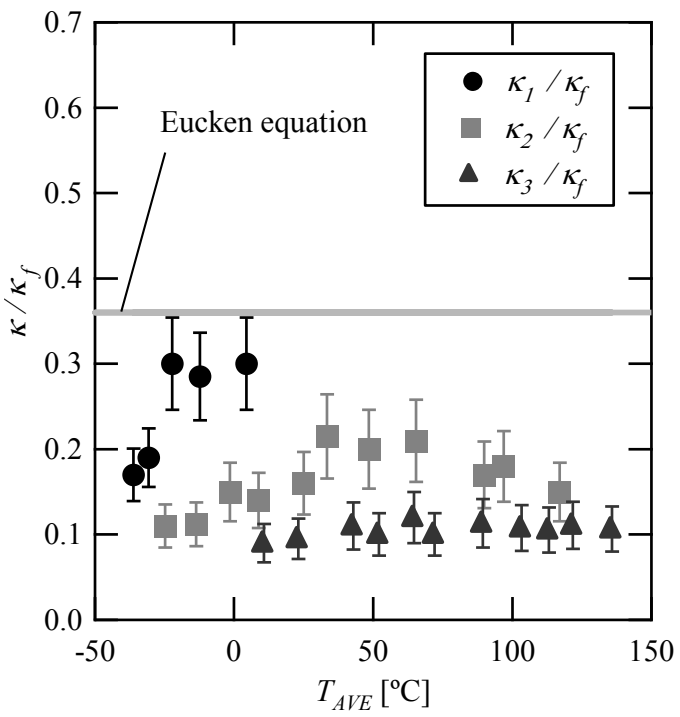

Fig.9 Measured thermal conductivity of porous Si thin films

気伝導率比は各パターン間で大きな差は見られなかった。 これよりエレクトロンの平均自由行程は構造より小さく, 構造中でバルクのように拡散輸送をしていると説明でき る. 多孔構造の空隙率から電気伝導率を予測する Maxwell の式[13]を用いて空隙率を計算したところ, 構造部の空隙 率は $52 \%$ \%った。一方で熱伝導率は電気伝導率と異なり, 各パターンにおいて異なる応答を示し, 孔の配置の違い により大きな影響を受けた。このときパターン 1 におい て測定温度を上げると電気的特性が一様にならず事前に 測定した電気抵抗の温度依存性の条件から外れたため熱 伝導率の測定ができなかった. ブリッジ部の電気伝導率 より Wiedemann-Franz の法則から電子の寄与する熱伝導 率を求めるといずれのパターンも $1.0 \times 10^{-5}[\mathrm{~W} /(\mathrm{m} ・ \mathrm{~K})]$ 程 度となった。 熱伝導はフォノン輸送が主であるため, パ ターンによる熱伝導率の変化はフォノンの輸送形態の変 化によるものと考えられる. 3 種類のパターンを比較した ところ熱伝導率は孔の配列を変えずに孔間隔を狭くする よりも, 孔間隔を変えずに千鳥状に配列する方が熱伝導 率は大きく減少した。 高温ではその差は小さいが, 低温 になるほど千鳥状の構造を有するマイクロブリッジの熱 伝導率は減少している。これは微細構造中でフォノン輸 送が準弾道輸送となり, 格子状に孔を配列した場合に孔 の間を通る構造の影響を受けないフォノンが千鳥状に孔 
を配列することで影響を受けやすくなったからだと考え られ, 孔の配置によるフォノン輸送への影響を評価した 先行研究と同様の傾向を示している[14]. 室温における $\mathrm{Si}$ のエレクトロンの平均自由行程は $100 \mathrm{~nm}$ 程度と短いが フォノンの平均自由行程は長いもので数 $10 \mu \mathrm{m}$ まで達す る[15-18]. Si では, 構造が数 $\mu \mathrm{m}$ 程度となると, 孔のサイ ズだけでなく，孔配列の違いでも熱伝導率を低減できる ことを示している.図9の直線は空隙率 52\%として Eucken の式[19]から求めた熱伝導率であり, 実験で得られた熱伝 導率は予測值よりも低い. Eucken の式ではフォノンの拡 散輸送が暗黙のうちに仮定されている。しかし上記で述 ベたように $\mathrm{Si}$ のフォノンの平均自由行程が長いことから, マイクロブリッジ中ではフォノンが準弾道輸送しており, その際熱伝導率は低減する。低温においてフォノンの平 均自由行程は伸びるが, 構造のあるパターンの熱伝導率 の低減が低温でやや大きくなることもつじつまが合って いる. 構造のない Si 薄膜の熱伝導率をレーザー周期加熱 法[20]によって室温で測定すると $\kappa_{f}(=87 \mathrm{~W} /(\mathrm{m} \cdot \mathrm{K}))$ はバ ルク $\mathrm{Si}$ の熱伝導率の $58 \%$ となり, 同程度の薄膜 $\mathrm{Si}$ の熱伝 導率測定結果ともよく一致していた[21]. これは薄膜化に よるフォノンの表面散乱の増加による影響であると考え られる. 熱伝導率の減少率から Fucks-Sondheimer の式[22] を用いて膜厚を代表長さとするフォノンの $K n$ 数をフィッ ティングパラメーターとした解析を行うとフォノンの平 均自由行程が $3 \mu \mathrm{m}$ 程度と概算される. 薄膜化によるフォ ノン散乱の影響だけでなく数 $\mu \mathrm{m}$ 程度の微細孔構造を設 けることで構造界面の影響によりフォノンが散乱し, 準 弾道的な輸送をしているため熱伝導率は減少したと考え られる. したがって室温でも数 $\mu \mathrm{m}$ 程度の微細構造におい ては, フォノン輸送特性と電子輸送形態が異なり, フォ ノン輸送は準弾道輸送，電子輸送は拡散輸送になってい ると考えられる.

\section{5. 結論}

MEMS技術を用いて微細孔構造を持つSi薄膜マイクロ ブリッジを作製し, 通電加熱法により面方向の熱伝導 率・電気伝導率を測定した。微細孔構造により, 電気伝 導率の減少率は構造によって大きな違いが見られなかっ たが，熱伝導は孔構造の違いによって異なる応答を示し，
空隙率が同じでも, 孔の配置, 孔間隔の違いにより異な る熱伝導率が測定された。これはフォノンと電子の平均 自由行程の差によって考察でき, 微細構造よりも大きな 平均自由行程を持つフォノンの輸送は準弾道輸送となり, 電子輸送は拡散輸送となっているためと考えられる.

\section{謝辞}

本研究は, 独立行政法人新エネルギー・産業技術開発機構 (NEDO)による異分野融合型次世代デバイス製造技術開 発プロジェクト (BEANS)の一環として行われた. 研究を 進めるにあたり財団法人ファジィシステム研究所から温 かい助言を頂いたこと, 研究室を修了した鶴慶彦君と川 原庸資君に協力頂いたことを記して謝意を表する.

\section{参考文献}

[1] P. B. Joyce, T. J. Krzyzewski, G. R. Bell, B. A. Joyce and T. S. Jones; "Composition of InAs quantum dots on GaAs (001): Direct evidence for (In, Ga) As alloying", Phys. Rev. B, 58 (1998) 981-984.

[2] M. S. Gudiksen, L. J. Lauhon, J. Wang, D. C. Smith, C. M. Lieber; "Growth of nanowire superlattice structures for nanoscale photonics and electronics", Nature, 415 (2002) 617-620.

[3] A. I. Hochbaum, R. Chen, R. D. Delgado, W. Liang, E. C. Garnett, M. Najarian, A. Majumdar, P. Yang; "Enhanced thermoelectric performance of rough silicon nanowires", Nature, 451 (2008) 163-168.

[4] R. Venkatasubramanian; "Lattice thermal conductivity reduction and phonon localizationlike behavior in superlattice structures", Phys. Rev. B, 61 (2000) 3091-3097.

[5] R. Venkatasubramanian, E. Siivola, T. Colpitts B. O’Quinn; "Thin-film thermoelectric devices with high room-temperature figures of merit", Nature, 413 (2001) 597-602.

[6] D. Song, G. Chen; "Thermal conductivity of periodic microporous silicon films", Appl. Phys. Lett., 84 (2004) 687-689.

[7] M. Kashiwagi, S. Hirata, K. Harada, Y. Zheng, K. Miyazaki, M. Yahiro, C. Adachi; "Enhanced figure of merit of a porous thin film of bismuth antimony telluride", Appl. Phys. Lett., 98 (2011) 023114.

[8] P.E. Hopkins, C.M. Reinke, M.F. Su, R.H. Olsson, Z.C. Leseman, J.R. Serrano, L.M. Phinney and I. El-Kady; "Reduction in the Thermal Conductivity of Single Crystalline Silicon by Phononic Crystal Patterning”, Nano Lett. 11 (2011) 107-112.

[9] M. Takashiri, K. Miyazaki, S. Tanaka, J. Kurosaki, D. 
Nagai, and H. Tsukamoto; "Effect of grain size on thermoelectric properties of n-type nanocrystalline bismuth-telluride based thin films", J. Appl. Phys., 104 (2008) 084302.

[10] 田中三郎, 高尻雅之, 宮崎康次 ; $「 \mathrm{Bi}_{0.4} \mathrm{Te}_{3.0} \mathrm{Sb}_{1.6}$ ナノ 多孔体の熱伝導率」，熱物性， 24 (2010) 94-100.

[11] Y. C. Tai, C. H. Mastrangelo and R. S. Muller; "Thermal conductivity of heavily doped low-pressure chemical vapor deposited polycrystalline silicon films", J. Appl. Phys., 63 (1988) 1442-1447.

[12] X. Zhang, I. Hatta, S. Fujiwara, M. Fujii; "Measurements of Thermal Conductivity and Electrical Conductivity of a Single Carbon Fiber", Int. J. Thermophysics, 21 (2000) 965-980.

[13] J.C. Maxwell; "A Treatise on Electricity and Magnetism", 3rd ed. 1 (1904) 435-441, Oxford University Press, Cambridge.

[14] K. Miyazaki, T. Arashi, D. Makino, H. Tsukamoto, "Heat conduction in microstructured materials", IEEE trans. on CPMT, 29 (2006) 247-253.

[15] N. W.Ashcroft, N. D. Mermin; "Solid State Physics", (1976) Saunders College Publishing.

[16] S. M. Sze; "Physics of Semiconductor Devices", (1981) John Wiley \& Sons.
[17] N. Savvides, H. J. Goldsmid; "Boundary scattering of phonons in silicon crystals at room temperature", Phys. Lett. A, 41, (1972) 193-194.

[18] C. Dames and G. Chen; "Theoretical phonon thermal conductivity of Si/Ge superlattice nanowires", J. Appl. Phys., 95 (2004) 682-693.

[19] Eucken, A; "Allgemeine gesetzmäßigkeiten für das wärmeleitvermögen verschiedener stoffarten und aggregatzustände", Forschung auf dem Gebiet des Ingenieurwesens (Ausgabbe A) 11 (1940).

[20] R. Kato, A. Maesono, R. P. Tye, I. Hatta. "Thermal diffusivity by modified ac calorimetry using a modulated laser beam energy source", Int. J. Thermophysics, 20, (1999) 977-986.

[21] Marconnet, Amy M, M. Asheghi, and K. E. Goodson. "From the Casimir Limit to Phononic Crystals: 20 Years of Phonon Transport Studies Using Silicon-on-Insulator Technology", J. Heat Trans., 135 (2013) 061601.

[22] M. Asheghi, M. N. Touzelbaev, K. E. Goodson, Y. K. Leung, S. S. Wong; "Temperature-dependent thermal conductivity of single-crystal silicon layers in SOI substrates", J. Heat Trans., 120 (1998) 30-36.

[Received Sep. 28, 2013 , Accepted May 28, 2014] 